\title{
INFLUENCE OF SOCIO-DEMOGRAPHIC CHARACTERISTICS ON ACTIVITY TRAVEL BEHAVIOUR OF COMMUTERS IN A MEDIUM SIZED CITY IN INDIA
}

\author{
Sreela Parambath Koyilerian ${ }^{1}$, M V L R Anjaneyulu ${ }^{2}$ \\ ${ }^{1}$ Government Engineering College, Kozhikode, Kerala, India \\ ${ }^{2}$ National Institute of Technology, Calicut, Kerala, India
}

Received 24 August 2021; accepted 26 September 2021

\begin{abstract}
Technological developments in small or medium sized cities are often at a slower rate due to the lack or scarcity of funds. Proper planning of facilities in such cities should hence be executed meticulously. This requires an understanding of travel needs of individuals. As majority of the travel are made for work the study aims to explore the activity and travel preferences of workers. Majority of the commuters are likely to travel at the same time of day, causing congestion during peak hours. Under these circumstances, it is essential to explore the commuting behaviour of individuals. It also aids transportation engineers and planners to recognise individual preferences for arriving at user friendly strategies and a sustainable environment. The aim of the study is to identify the travel related choice of work commute. These choice dimensions are explored through activity participation model, mode and time of day choice models using multinomial and binary logit modelling approaches incorporating the socio-demographic characteristics. Modelling results underscore the importance of variables like gender, age and presence of school children on an individual's decision to commute. The study indicates that majority of the workers prefer public transportation for commuting. They are more likely to commute between $8 \mathrm{am}$ to $10 \mathrm{am}$ in the morning. Scenario analyses were done to understand the shifts in travel mode of workers, with changes in travel time. These results highlight the substantial impact of travel time on mode share of commuters in the area.
\end{abstract}

Keywords: socio-demographic, participation, mode choice, time of day.

\section{Introduction}

Cities are centres of trade, commerce, cultural and political activities and have a major role in their economic growth and development of any country. A good transportation system is essential to facilitate easy and faster movement to various places of activities in cities. In the case of developing countries like India, a substantial share of the annual budget is devoted to the planning and development of transportation facilities in metropolitan cities. Little attention and funding are provided for infrastructure development in medium-sized cities, which form a major share. However, a medium city is also experiencing rapid growth in terms of population and vehicular traffic. Planning of transportation facilities in medium cities is crucial to the balanced and sustainable

${ }^{1}$ Corresponding author: pksreela@geckkd.ac.in 
growth in the country, which demands a good understanding of the travel needs of individuals in such cities.

Commuting is the regular activity of travelling between residence and workplace, with a large impact on contemporary life. It has resulted in the growth of cities and has led to the spread of urban boundaries. The decision to work is one of the most important choices affecting an individual as all other activity participation performed by a worker is partially dependent on this decision.

Mode choice is an important component of travel behaviour analysis that determines the probability of choosing a particular mode of travel. The desirability of a travel mode is determined by the utility of the particular mode. Work mode choice models aids to evaluate the ability of traffic-congestion measures and also to determine the feasible mode based on their choice set (Bhat, 1997). Majority of the earlier studies were reported in the developed countries with structured transport network and facilities. In a developing country, the facilities are poor, with lots of congested facilities, resulting in crowded roads and lack of funds. In such countries, affordability also has an important role in determining choice set (Enam and Choudhury, 2011).

Choice of time of day is an important decision process that influences the temporal dimensions of travel demand. In the activitybased modelling method, it is possible to consider periods of shorter duration than simply morning peaks, mid-day peaks or evening peaks. Majority of the commuters are likely to travel at the same time of day, causing congestion during morning and evening peak hours.
Improper design and scheduling of public transportation also contribute to congestion during peak hours and hence fails to cope with the peak demands. Under these circumstances, it is essential to explore the commuting behaviour of individuals. The objectives of the research are to explore the influence of socio-demographic variables on the worker's decision to commute, to discover the mode choice behaviour of workers for commute, to understand the time-of- day choice behaviour of workers for commute and scenario analysis. Majority of the comprehensive models for travel demand forecast in the country were developed only in some of the metropolitan cities due to the availability of funds of such cities. In the case of medium-sized cities, comprehensive mobility plans are rarely prepared due to scarcity of funds. These cities are also facing severe congestion due to high population growth, high vehicle ownership and lack of good public transportation system. Hence it is very essential to explore the travel behaviour of workers in such regions.

\section{Study Area and Data Collection}

Calicut city, a medium-sized city, is the commercial capital of Malabar region and the northern part of Kerala, India. The population of Calicut Corporation is 0.6 million as per 2011 census. It spreads over an area of $118.59 \mathrm{sq}$. kms. and has a population density of 5171 per sq. $\mathrm{km}$. The connectivity within the city is limited to the road network of density $2.824 \mathrm{kms}$ per sq. $\mathrm{km}$. Kappad beach in Calicut is famous as the Portuguese explorer Vasco Da Gama landed in this beach in Calicut in 1498. The city is divided into 71 wards for administrative purposes. 


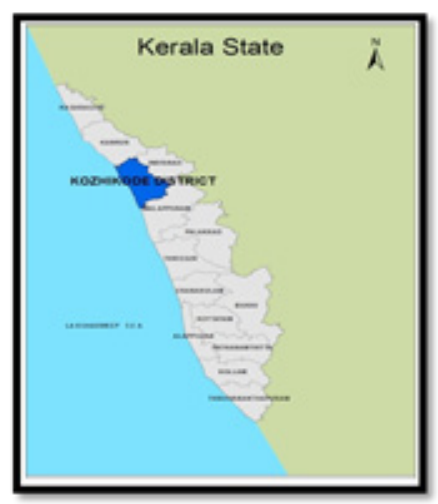

Fig. 1.

Map of the Study Area

Data was collected from 9901 households spread over the whole study area in the year 2010. Activity and travel details of one day were collected from all members of the randomly selected households. Activity travel diary was used for collecting data. Fig. 1 shows the map of the study area. Travel behaviour analysis in activity based approach requires time-use survey data for analysis and forecasting. Therefore an activity travel diary was designed to capture the details of all trips and activities performed by individuals. After the preparation of activity diary, a pilot survey was conducted to evaluate the performance of the questionnaire format (Richardson et al., 1995). The questionnaire was finalised based on the feedback of pilot survey. It consists of three parts: household information, personal information and activity- travel information. It is well designed to capture the entire details of trips and activities performed by the individual along with personal and household information. Proper co-ordination and monitoring of survey is essential for reliable data, or it will result in some type of errors (Stopher and Sheskin, 1982). Therefore trained enumerators were employed for the data collection by home

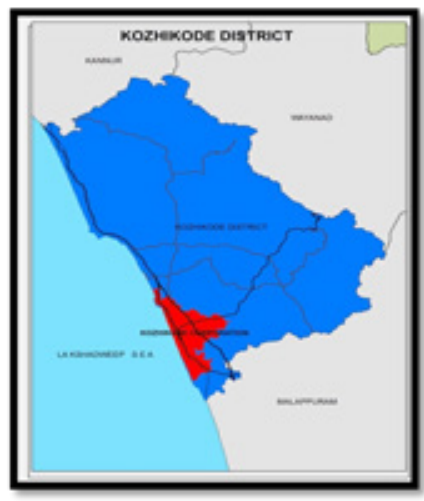

interview survey, using face to face interview technique. The residents were informed about the importance of the survey through newspapers. Activity and travel details of 39637 persons formed the main database for the study. The working population considered for the study is 7700 .

\subsection{Preliminary Analysis of Data}

A preliminary analysis of the data was done to understand the general characteristics of the area. Trip rate per household is 4.4 and trip rate per person in 2.07. Nearly $21 \%$ of individuals are graduates. The analysis exhibited that on an average there are 4 members per household. The average monthly income of household is INR 23444. Average automobile ownerships per household, car ownerships and twowheeler ownerships are $0.857,0.278$, and 0.579 respectively. The average employee per household is 1.32 . The analysis implies that the majority of people in the study area belong to the working population (4156) and a majority of trips are related to work. The distribution of male and female population in the sample is $49 \%$ and $51 \%$ respectively. The present study observed 
a male to female ratio of 0.96 . This section describes the general characteristics of the household, including household size, household income, household automobile, household occupation; household males and females. In the activity-based modelling context, travel decisions made by households are the result of the interactions among household members. The household size is thus an important factor affecting travel decisions. Fig. 2. shows the distribution of sampled households based on size.

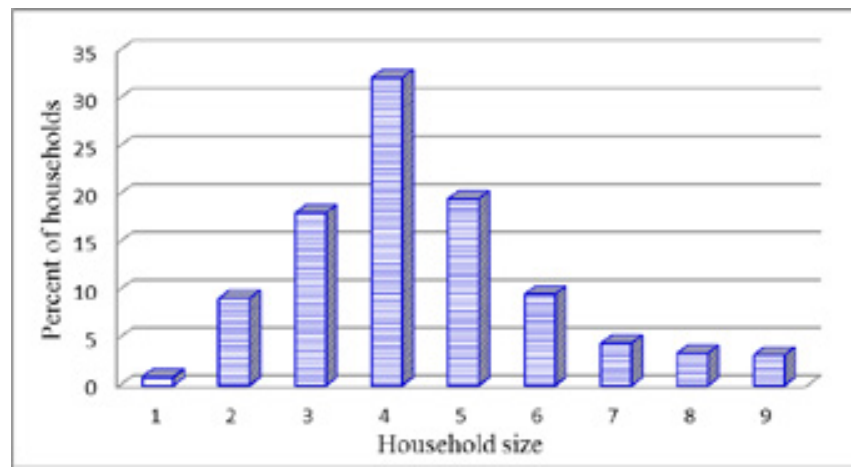

Fig. 2.

Distribution of Households based on Size

The distribution of trips by travel mode is shown in Fig. 3. It is observed that majority of the people travel by bus (38\%). The share of car and two-wheeler is $10.96 \%$ and $23.9 \%$ respectively. People travel least by bicycle (1.33\%).

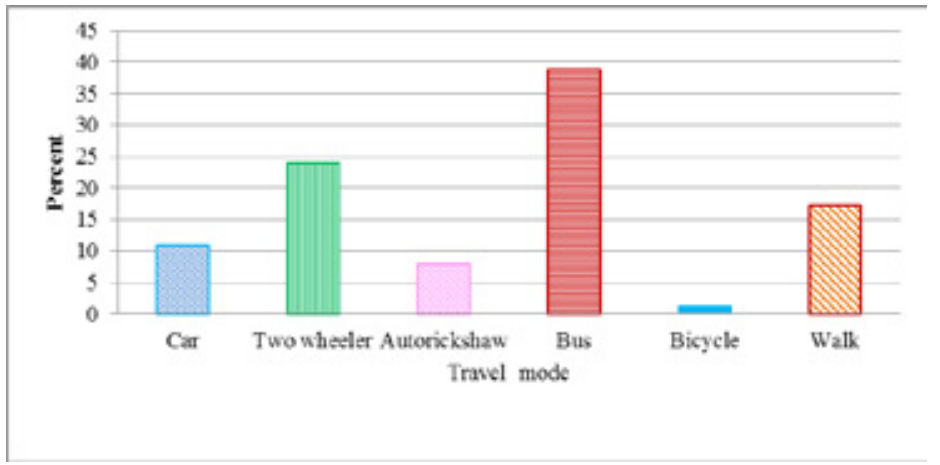

Fig. 3.

Distribution of Trips by Various Travel Modes

Analysis performed on activity and travel characteristics revealed a variety of travel patterns of the study population. The different types of simple pattern are shown in Fig. 4. It indicates that the majority of the simple activity pattern is performed by workers for the commute. 


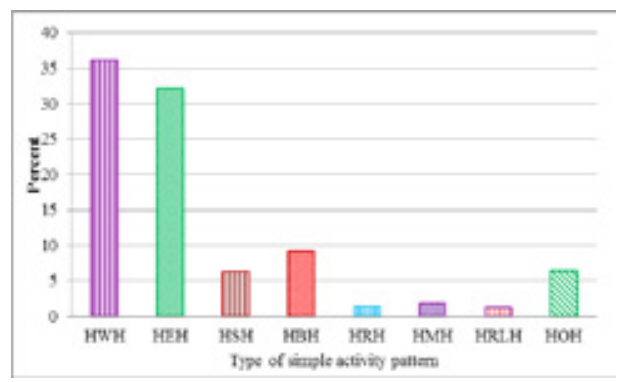

Fig.4.

Distribution of Simple Activity Patterns

\section{Modelling Methodology}

The main objective is to explore the influence of socio demographics on commute behaviour of workers. This requires the development of models to describe the influence of household activity and travel variables on an individual's decision to commute. The decision to commute or not is modelled using the binary logit model as there are only two choices involved. Mode choice model is calibrated using Multinomial logit model (MNL), the most commonly adopted discrete choice model for real-world applications. The different alternatives are car, two-wheeler, auto-rickshaw, bus and walk. For the development of time-ofday choice models, the day is divided into different periods of two hours duration: i Early morning from 4.00 a.m. to 6.00 a.m.;

ii Morning (M) from 6.00 a.m. to 8.00 a.m.;

iii Morning peak 8.00 a.m. to 10.00 a.m.;

iv Late morning from 10.00 a.m. to 12.00 noon.

Time of day choice models are also developed using MNL models.

\subsection{Activity Participation Model}

Three categories of variables are considered for modelling. These relate to socioeconomic characteristics, activity and travel. Table 1 presents the influence of variables on workers decision to commute or not.

\section{Table 1}

Work Participation Model Estimates

\begin{tabular}{|l|l|}
\hline Variable & Coefficients \\
\hline Constant & $3.633(15.459)$ \\
\hline Presence of school students (Dummy) & $0.397(3.844)$ \\
\hline Age & $-0.032(-7.977)$ \\
\hline Gender (Dummy) & $0.300(3.576)$ \\
\hline The goodness of fit measures & \\
\hline LL (Constant) & -1533.31 \\
\hline LL (Convergence) & -1194.53 \\
\hline Chi-squared & 677.55 \\
\hline $\mathrm{R}^{2}$ & 0.221 \\
\hline Adjusted $\mathrm{R}^{2}$ & 0.218 \\
\hline \multicolumn{1}{|c|}{ Predicted (\%) } & 92.45 \\
\hline $\mathrm{N}$ & 5501 \\
\hline
\end{tabular}


Among the socio-economic variables, the effect of age indicates that as age increases the workers are less likely to commute. Gender is a strong determinant of engagement in work activity; the positive influence indicates that men are more likely to commute. These results are consistent with the traditional role of women as a caretaker (Ory and Mohktarian, 2005). The study observes the influence of school children on worker's decision to commute. The influence of children on commute behaviour is well documented in the literature (Williams, 1995; Barkume and Horvath, 1995; Lu and Pas, 1999). Even though activity and travel variables are used in modelling they are not found to influence the commuting behaviour of working people. The decision to commute is thus influenced largely by the socio-demographics.

\subsection{Modelling Worker's Decision to choose Commute Mode}

Data of 5500 workers participating in work is used for the analysis. The various alternatives are car, two-wheeler, auto-rickshaw, bus and walk. The individual socio-demographic characteristics are reflected through age, education, gender, and vehicle availability for personal use.

The household demographics are household size, number of students in the household and the household structure representing households consisting of workers and school students. The activity and travel variables are travel time, ride-sharing, work duration and activity pattern. Table 2 presents the model estimates and the influencing variables.

Table 2

Mode Choice Model Estimates for Work Commute

\begin{tabular}{|c|c|c|}
\hline Alternative & Variables & Coefficient-t statistic \\
\hline \multirow{4}{*}{ Constants } & Car & $-3.100(-7.416)$ \\
\hline & Walk & $-9.350(-2.500)$ \\
\hline & Auto-rickshaw & $-1.093(-2.641)$ \\
\hline & Bus & $0.228(3.558)$ \\
\hline \multirow{7}{*}{ Car } & Household school students (Dummy) & $0.316(3.549)$ \\
\hline & Travel time & $-0.961(-13.801)$ \\
\hline & Vehicles per person & $0.671(4.419)$ \\
\hline & Age & $0.032(8.497)$ \\
\hline & Work duration & $1.550(4.540)$ \\
\hline & Education (Dummy) & $0.670(6.436)$ \\
\hline & Ridesharing (Dummy) & $1.079(10.790)$ \\
\hline Walk & Same zone (Dummy) & $3.602(4.940)$ \\
\hline \multirow{2}{*}{ Auto-rickshaw } & Gender (Dummy) & $-1.982(-9.954)$ \\
\hline & Travel time & $-0.861(-18.801)$ \\
\hline \multirow{6}{*}{ Bus } & Vehicles per person & $-5.304(-23.354)$ \\
\hline & Same zone (Dummy) & $-0.651(-4.535)$ \\
\hline & Household students (Dummy) & $-0.512(-5.703)$ \\
\hline & Household size & $-0.164(-5.571)$ \\
\hline & Activity pattern (Dummy) & $0.865(5.760)$ \\
\hline & Travel time & $-0.361(-30.801)$ \\
\hline \multirow{4}{*}{ Goodness of Fit Measures } & LL (Constant) & -10183.8 \\
\hline & LL (Convergence) & -5137.28 \\
\hline & Chi-squared & 10093.23 \\
\hline & $\mathbf{R}^{2}$ & 0.49 \\
\hline
\end{tabular}


The model reflects the higher attraction potential of public transportation for commuting. The coefficient of travel time is negative. This suggests that travellers usually prefer mode that enables them to make a trip in less time. Travel time of public transportation is perceived as less negative than the travel time for private modes. A similar influence was observed in earlier studies in India and other countries by (Muralidhar et al., 2006; Ghareib, 1996; Roorda et al., 2009; Bhat, 1997; Habib, 2012; Yang et al., 2010; and Hensher and Rose, 2007). The positive influence of school students on commuters car choice is a simple reflection of adults travelling with children for escorting, Bhat (1997). Influence of the variable "sharing ride" is an indication of the presence of colleagues, spouse or children, working or studying in the proximity of the commuter's work place. The model reveals the positive significance of vehicles per persons to commute. Work duration also influences worker's decision to commute by car. Similarly, elder workers are more likely to commute by car. Influence of age and gender on commute mode choice was well documented in the literature ( $\mathrm{Li}$ et al., 2005; Roorda et al., 2009; and Mensah, 1995).The workers are less likely to choose a bus if the workplace is in the neighbourhood of residence. The results also indicate that in case if the work and residence are in the same neighbourhood, the workers are more likely to walk to the work place. Gender is the only personal variable influencing autorickshaw choice.

\subsection{Modelling Worker's Decision to choose Time of Day for Commute}

Time-of-day choice is an important travel decision that influences the temporal dimensions of travel. These models provide information regarding the time at which travel occurs in a day and is an important component of the overall travel decisionmaking process. It helps to plan new facilities and to explore the effectiveness of various time-of-day specific travel demand management measures. Time-of-day choice model estimates of worker's commute are presented in Table 3. The model constants indicate that the workers are likely to start for work during the morning peak hours.

\section{Table 3}

Time-of-day Model Estimates for Commute

\begin{tabular}{|c|c|c|c|}
\hline Variable & $\begin{array}{l}\text { Morning } \\
(6 \text { to } 8)\end{array}$ & $\begin{array}{l}\text { Morning peak } \\
\quad(8 \text { to } 10)\end{array}$ & $\begin{array}{l}\text { Late morning } \\
\quad(10 \text { to } 12)\end{array}$ \\
\hline Constant & $1.864(2.614)$ & $3.854(5.663)$ & $1.426(1.997)$ \\
\hline \multicolumn{4}{|l|}{ Household variables } \\
\hline $\begin{array}{l}\text { Employed couples and school students } \\
\text { (Dummy) }\end{array}$ & & $0.709(2.048)$ & \\
\hline $\begin{array}{l}\text { Household vehicles per person } \\
\text { (Dummy) }\end{array}$ & & $1.187(2.628)$ & $1.259(2.593)$ \\
\hline \multicolumn{4}{|l|}{ Personal variables } \\
\hline Gender (Dummy) & & $-1.085(-2.820)$ & \\
\hline Age & $0.02(2.192)$ & $-0.005(-2.686)$ & \\
\hline \multicolumn{4}{|l|}{ Travel-variables } \\
\hline Two-wheeler choice (Dummy) & & $1.274(2.635)$ & $1.271(2.043)$ \\
\hline Bus choice (Dummy) & & $0.895(2.026)$ & \\
\hline Travel time & & $-0.030(-2.92)$ & $-0.06(-4.758)$ \\
\hline
\end{tabular}




\begin{tabular}{|l|l|l|l|}
\hline \multicolumn{1}{|c|}{ Variable } & \multicolumn{1}{|c|}{$\begin{array}{c}\text { Morning } \\
(6 \text { to } 8)\end{array}$} & $\begin{array}{c}\text { Morning peak } \\
(8 \text { to 10) }\end{array}$ & $\begin{array}{c}\text { Late morning } \\
\text { (10 to 12) }\end{array}$ \\
\hline The goodness of fit measures & -6956.66 \\
\hline LL(Constant) & -5866.61 \\
\hline LL (Convergence) & 1110.10 \\
\hline Chi-squared & 0.157 \\
\hline $\mathrm{R}^{2}$ & 0.155 \\
\hline Adjusted $\mathrm{R}^{2}$ & $73 \%$ \\
\hline Predicted & 4700 \\
\hline $\mathrm{N}$ & Early morning \\
\hline Base alternative &
\end{tabular}

Employed couples with school students are likely to commute during the morning peak hours as the students are likely to be accompanied to school by their parents. Vehicles per person also influence the worker's decision to commute in the morning peak and late morning hours due to the flexibility of private vehicles. Male workers are less likely to commute during morning peak hours. The bus users are more likely to commute during morning peak hours. Travel time indeed influences the time of day choice of commuting. Age is another variable affecting the time of day choice for commuting.

\section{Scenario Analysis}

The models developed focuses on the different dimension of activity and travel choice of individuals. Travel time was found to influence the mode choice behaviour of commuters. Hence scenario analysis was performed using travel time, being one of the important policy variables. The scenario analysis was conducted by increasing and decreasing travel time of car, bus and twowheeler and the corresponding shift in mode choice was determined. The following are the scenarios used in the study:
- Increasing travel time by $10 \%$;

- Increasing travel time by $25 \%$;

- Decreasing travel time by $10 \%$;

- Decreasing travel time by $25 \%$.

\subsection{Increasing Travel Time of Car by $10 \%$}

It indicates that a $10 \%$ increase in travel time by car, reduces the mode share of a car by $4 \%$. This causes an increase in the probability of choosing two-wheeler and bus by an equal share of $1.2 \% .10 \%$ increase in travel time of two-wheelers was observed to reduce the share of a car by $14 \%$ and two-wheelers by $9 \%$. An increase in the share of public transport by $18 \%$ was also observed. This resulted in a marginal increase in the share of auto-rickshaw by $2 \% .10 \%$ increase in travel time of bus resulted in the reduction of bus usage by $6 \%$. This caused an increase in the share of a car by $9 \%$ and auto-rickshaw by $3 \%$.

\subsection{Decreasing Travel Time by $10 \%$}

The results of scenario analysis are tabulated in Table 5 . There is a $6 \%$ increase in the mode share of a car when the travel time of the car is reduced by $10 \%$. A decrease of $2 \%$ in the mode share of a bus is observed. 
A small increase in the share of two-wheeler is also observed. There is an increase of $7 \%$ in the mode share of car and $1.6 \%$ in the mode share of two-wheeler when the travel time of two-wheeler is reduced by $10 \%$. A $4 \%$ decrease in the mode share of the bus is reflected by this change in travel time. When there is a decrease of $10 \%$ in the travel time of a bus, the share of bus increases by $6 \%$ and the share of car increases by $8 \%$. Modes share of two-wheeler shows a reduction of $4 \%$.

\section{Table 5}

Mode Share for a 10\% Decrease in Travel Time

\begin{tabular}{|l|c|c|c|c|c|}
\hline \multirow{2}{*}{\multicolumn{1}{|c|}{ Scenario }} & \multicolumn{5}{c|}{ Mode Share } \\
\cline { 2 - 7 } & Car & Two-Wheeler & Auto-Rickshaw & Bus & Walk \\
\hline Present probability & 0.069 & 0.001 & 0.037 & 0.331 & 0.001 \\
\hline $10 \%$ decrease in travel time of car & 0.073 & 0.564 & 0.037 & 0.325 & 0.001 \\
\hline $10 \%$ decrease in travel time of two-wheeler & 0.074 & 0.571 & 0.037 & 0.317 & 0.001 \\
\hline $10 \%$ decrease in travel time of bus & 0.075 & 0.536 & 0.037 & 0.351 & 0.001 \\
\hline
\end{tabular}

\subsection{Increasing Travel Time by $25 \%$}

The results of scenario analysis are tabulated in Table 6. If the travel time of a car is increased by $25 \%$, the mode share of the car reduces by $10 \%$. The resulting share of auto-rickshaw increases by $5 \%$. There is an increase of $0.3 \%$ for bus and $0.7 \%$ for twowheeler. Mode share of a car reduces by $14 \%$ and two-wheeler by $3 \%$. This reduction in mode share resulted in an increase of $12 \%$ in the mode share of a bus. Mode share of auto-rickshaw increases by $2.7 \%$. Similarly other results are interpreted.

\section{Table 6}

Mode Share for a 25\% Increase in Travel Time

\begin{tabular}{|l|c|c|c|c|c|}
\hline \multicolumn{1}{|c|}{ Scenario } & \multicolumn{5}{c|}{ Mode Share } \\
\hline & Car & Two-Wheeler & Auto-Rickshaw & Bus & Walk \\
\hline Present probability & 0.069 & 0.566 & 0.037 & 0.331 & 0.001 \\
\hline $\begin{array}{l}25 \% \text { increase in } \\
\text { travel time of car }\end{array}$ & 0.062 & 0.566 & 0.039 & 0.332 & 0.001 \\
\hline $\begin{array}{l}25 \% \text { increase in } \\
\text { travel time of two-wheeler }\end{array}$ & 0.049 & 0.543 & 0.038 & 0.329 & 0.001 \\
\hline $\begin{array}{l}25 \% \text { increase in } \\
\text { travel time of bus }\end{array}$ & 0.06 & 0.591 & 0.037 & 0.288 & 0.001 \\
\hline
\end{tabular}

\subsection{Reducing Travel Time by $25 \%$}

Table 7 indicates the results for reducing the travel time by $25 \%$. When there is a $25 \%$ reduction in travel time of bus there is an increase in the mode share of a bus by $26 \%$ and a large decrease in the mode share of all other modes. This is an important finding that will aid public transportation improvement in the city. 
Table 7

Mode Share for a 25\% Decrease in Travel Time

\begin{tabular}{|l|c|c|c|c|c|}
\hline \multirow{2}{*}{\multicolumn{1}{|c}{ Scenario }} & \multicolumn{5}{c|}{ Mode Share } \\
\cline { 2 - 6 } & Car & Two-Wheeler & Auto-Rickshaw & Bus & Walk \\
\hline Present probability & 0.069 & 0.566 & 0.037 & 0.331 & 0.001 \\
\hline $\begin{array}{l}25 \% \text { decrease in } \\
\text { travel time of car }\end{array}$ & 0.079 & 0.558 & 0.037 & 0.325 & 0.001 \\
\hline $\begin{array}{l}25 \% \text { decrease in } \\
\text { travel time of two-wheeler }\end{array}$ & 0.06 & 0.584 & 0.036 & 0.319 & 0.001 \\
\hline $\begin{array}{l}25 \% \text { decrease in } \\
\text { travel time of bus }\end{array}$ & 0.06 & 4 & 0.036 & 0.419 & 0.001 \\
\hline
\end{tabular}

\section{Conclusion}

Major determinants of work commuting are observed to be age, gender and presence of students in the household. The workers are more likely to use a bus for commuting. Buses are also the most preferred mode for simple activity pattern of commute. This represents the better accessibility of public transportation in the area. This finding can be a major contribution to planning public transportation improvements in Calicut. Work duration and activity pattern are the only activity variables influencing mode choice. This represents the flexibility of private vehicle for personal use. The workers are likely to start for work during peak hours in the morning ( 8 am to 10 $\mathrm{am})$. The empirical results presented in this study demonstrate that these models are suitable for predicting the commuters' travel behaviour in the area. The study also clarifies that various socio-demographics have an impact on various travel choices of commuters in Calicut city. The scenario analysis indicates that a $25 \%$ decrease in travel time of public transportation resulted in an increase of $26 \%$ increase in the mode share of public transportation. It also shows a decrease in the mode share of cars and twowheelers by $3 \%$ and $15 \%$ respectively. The scenario analysis indicates that if the travel time of public transportation is reduced, more people are likely to choose this mode over private vehicles. Studies in this line are expected to assist planners in the formulation and implementation of efficient travel demand management strategies and the need for public transportation improvements in future.

This work is one of the initial efforts to comprehend the activity-travel behaviour of workers in a medium-sized city in India. This work can aid transport planners in the city to provide insights for better estimates of travel demand and a major contribution to the planning of employment opportunities based on gender. The study confirms that even in medium sized cities the travel behaviour of workers is highly influenced by personal, household, activity and travel variables.

The limitations of the study is that it does not consider the simultaneous choice of individuals and models are developed using simple and widely used binary and multinomial logit models. Another limitation is that it does not explicitly consider the interaction between various household members in the study. 


\section{Acknowledgments and Declarations}

The authors sincerely acknowledge the funding from the Ministry of Urban Development, Government of India through the Centre of Excellence (CoE) in Urban Transport and Department of Civil Engineering, IIT Madras. The authors thank the residents of Calicut for their cooperation in the data collection process.

\section{References}

Barkume, A.J.; Horvath, F.W. 1995. Using Gross flows to explore movements in the labour force, Monthly Labor Review 118(4): 28-35.

Bhat, C.R. 1997. Work travel mode choice and a number of non-work commute stop, Transportation Research Part B 31(1): 41-54. Available from Internet: <http://hdl. handle.net $/ 2152 / 23985>$.

Enam, A.; Choudhury, C. F. 2011. Methodological Issues in Developing Mode Choice Models for Dhaka, Bangladesh, Transportation Research Record: Journal of the Transportation Research Board 2239 (1): 84-92. doi:10.3141/2239-10.

Ghareib, A. H. 1996. Evaluation of logit and probit models in mode-choice situation, Journal of Transportation Engineering 122(4): 282-290.

Habib, K. M. N. 2012. Modeling commuting mode choice jointly with work start time and work duration, Transportation research part A: Policy and practice 46(1): 33-47.

Hensher, D. A.; Rose, J. M. 2007. Development of Commuter and Non Commuter Mode Choice Models for the Assessment of New Public Transport Infrastructure Projects: Case Study, Transportation Research Part A: Policy and Practice 41(5): 428-443.

Li, M. T.; Chow, L. F.; Zhao, F. 2005. Application of geographically stratified importance sampling in the calibration of aggregated destination choice models for trip distribution. In Proceedings of the 83th Annual meeting of the Transportation Research Board, Transportation Research Board, Washington, D.C.

Lu, X.; Pas, E.I. 1999. Socio-demographics, activity participation and travel behaviour, Transportation Research Part A 33(1): 1-18.

Mensah, J. 1995. Journey to work and job characteristics of the urban poor, Transportation 22(1): 1-19.

Muralidhar, B.; Mathew, T. V.; Dhingra, S. L. 2006. Prototype time-space diary design and administration for a developing country, Journal of Transportation Engineering 132(6): 489-498.

Ory, D.T.; Mokhtarian, P.L. 2005. Don'twork, work at home, or commute? Discretechoicemodels of the decision for San Francisco Bay Area residents. Research Report, Institute of Transportation Studies, University of California, Davis, USA. 35p.

Richardson, A.J.; Ampt, E.S.; Meyburg, A.H. 1995. Survey methods for Transport Planning. Eucalyptus Press, University of Melbourne, Australia. 75-145p. DOI: 10.4237/transportes.v5i1.272.

Roorda, M.J.; Passmore, D.; Miller, E.J. 2009. Including Minor Modes of Transport in a Tour-Based Mode Choice Model with Household Interactions, Journal of Transportation Engineering 135(12): 935-945.

Stopher, P. R.; Sheskin, I. M. 1982. Method for determining and reducing non-response bias, Transportation Research Record 886: 35-41.

Williams, D.R. 1995. Women's part-time employment: a gross flows analysis, Monthly Labor Review 118(4): 36-44.

Yang, M.; Wang, W.; Chen, X.; Wang, W.; Xu, R.; Gu, T. 2010. Modeling Destination Choice Behavior Incorporating Spatial Factors, Individual Socio demographics, and Travel Mode, Journal of Transportation Engineering 136(9): 800-810. 